\title{
Differences in UK healthcare professionals' knowledge, attitude and practice towards infliximab and insulin glargine biosimilars
}

\author{
Mohammed I. Aladul ${ }^{a, b}$ (D), Raymond W. Fitzpatrick ${ }^{a}$ and Stephen R. Chapman ${ }^{a}$ (DD \\ aSchool of Pharmacy, Keele University, Keele, UK and 'SSchool of Pharmacy, University of Mosul, Mosul, Nineveh, Iraq
}

\section{Keywords}

biosimilar; medical consultants; nurse;

pharmacist

\section{Correspondence}

Stephen R. Chapman, School of Pharmacy, Keele University, Hornbeam Building 3.06, Newcastle-under-Lyme, Staffordshire ST5 $5 B G, U K$

E-mail: s.r.chapman@keele.ac.uk

Received February 22, 2018

Accepted August 8, 2018

doi: 10.1111/ijpp.12485

\begin{abstract}
Objectives To investigate knowledge and attitudes of different healthcare professionals in UK towards infliximab and insulin glargine biosimilars

Methods UK medical consultants/registrars, nurses and pharmacists participated in anonymised, self-administered web-based survey distributed by professional associations.

Key findings There were 234 respondents: medical consultants/registrars (150), nurses (58) and pharmacists (26). $76 \%$ of medical consultants/registrars, $84 \%$ of pharmacists and $53 \%$ of nurses understood what biosimilars were. Medical consultants/registrars and pharmacists had safety and efficacy concerns when switching patients compared to initiation. Nurses had similar levels of safety and efficacy concerns about initiation.

Conclusion Healthcare professionals were more comfortable with the initiation of biosimilars than switching current patients. Medical consultants/registrars and pharmacists were more informed than nurses.
\end{abstract}

\section{Introduction}

Biosimilars are copies of approved and patent-expired biological medicines. In a financially constrained health system such as the UK National Health Service, the lower cost of biosimilars presents a significant potential cost saving. ${ }^{[1]}$ Up to February 2018, 38 biosimilars, corresponding to 14 molecules, were licensed in Europe. ${ }^{[2]}$ The more indications for biosimilars that are licensed, the more healthcare professionals (HCPs) are potentially prescribing them, but the relatively rapid introduction of biosimilars has resulted in a knowledge gap amongst HCPs. ${ }^{[3,4]}$ There are parallels with the early generics market; HCPs required a good understanding and knowledge before they were comfortable prescribing generics, so, it is likely that the same applies to biosimilars. ${ }^{[4]}$ Our study aimed to explore this potential gap in knowledge for infliximab and insulin glargine biosimilars and investigate, attitudes and practice towards these biosimilars amongst UK medical consultants, nurses and pharmacists.

\section{Methods}

This was an anonymised, self-administered web-based survey among UK medical consultants/registrars, nurses and pharmacists specialised in dermatology, diabetology, gastroenterology or rheumatology, conducted between August 2016 and January 2017.

The following associations were emailed and asked in turn to email potential participants an invitation letter with a link to the web survey; British Society of Gastroenterology, the British Society of Paediatric Gastroenterology Hepatology and Nutrition, the Welsh Association for Gastroenterology \& Endoscopy, the British Society for Medical Dermatology, the British Society for Paediatric Endocrinology and Diabetes, the Association of British Clinical Diabetologists, the British Dermatological Nursing Group, the Scottish Society for Rheumatology, the British Society for Rheumatology. This was followed by a reminder email trail four weeks after the initial email.

The survey questionnaire was developed from emerging themes in the current literature on biosimilars.

Questions identified respondents' professional discipline and workplace setting and investigated their knowledge, experience and opinions towards infliximab and insulin glargine biosimilars. Response options were either closed choices or Likert type scales. Responses were confidential 
with no personally identifying information; respondents consented by clicking an 'agree' button preceding the survey. The web survey tool enabled only fully completed responses to be submitted and utilised cookies to allow only one response per computer. The survey was piloted on a small number of HCPs and revised appropriately to eliminate redundancy and difficult or ambiguous questions. The survey responses were collected and summarised as number and percentage of responding HCPs using Survey Monkey. The study was approved by the Independent Peer Review Committee at Keele University.

\section{Results}

A total of $234 \mathrm{HCPs}$ participated in the survey. The highest proportion of responses were from medical consultants/registrars $(64 \%)(n=150)$ followed by nurses $25 \%$ $(n=58)$. The lowest response, $11 \%(n=26)$ was from pharmacists. Most of the survey participants were general hospital and tertiary centre-based HCPs (Table 1).

The majority, (76\%, $n=115)$, of medical consultants/ registrars, nurses $(53 \%, n=31 \%)$ and pharmacists $(84 \%$, $n=22$ ) thought biosimilars were copies of biological medicines. A minority of respondents $(6 \%, n=15)$ (mainly nurses) stated that they had heard about biosimilars but did not know what they were or had never heard about biosimilars. A large proportion of the medical consultants/registrars $80 \% \quad(n=121)$, pharmacists $80 \%$ $(n=21)$, and $57 \%$ of nurses $(n=33)$ were aware that biosimilars were available on their local formulary (Table 1).

Only $14 \%$ of consultants/registrars and 19\% of pharmacists had major concerns about safety or concerns which prevented them initiating a biosimilar. Similarly, $22 \%$ of consultants/registrars and $16 \%$ of pharmacists had major concerns about efficacy or efficacy concerns which prevented them initiating biosimilars. Twice as many nurses had the same safety (42\%) and efficacy (54\%) concerns (Figure 1).

When considering switching patients to a biosimilar, nurses had similar levels of concerns about safety (52\%) and efficacy $(63 \%)$ to initiation. In contrast, only $28 \%$ of medical consultants/registrars and $38 \%$ of pharmacists had concerns about safety and when initiating patients on a biosimilar, with similar levels of concern about efficacy when switching (34\% and 50\% respectively) (Figure 1).

Nearly all medical consultants/registrars (91\%) and nurses (96\%) weighted robust pharmacovigilance studies on biosimilars as the most important influence on their decision to increase prescribing of biosimilars, whereas 97\% of pharmacists weighted National Institute for Health and Care Excellence (NICE) guidance as more important. Medical consultants/registrars (27\%) and
Table 1 participants' characteristics, knowledge and awareness

\begin{tabular}{lccc}
\hline & $\begin{array}{l}\text { Consultants/ } \\
\text { registrars } \\
n=150\end{array}$ & $\begin{array}{c}\text { Nurses } \\
n=58\end{array}$ & $\begin{array}{l}\text { Pharmacists } \\
n=26\end{array}$ \\
\hline Speciality & & & \\
Dermatology & $20(13.3 \%)$ & $41(70.7 \%)$ & $0(0 \%)$ \\
\hline Diabetology & $49(32.6 \%)$ & $5(8.6 \%)$ & $4(15.4 \%)$ \\
Gastroenterology & $43(28.6 \%)$ & $2(3.5 \%)$ & $9(34.6 \%)$ \\
Rheumatology & $38(25.3 \%)$ & $10(17.2 \%)$ & $13(50 \%)$ \\
Work setting & $0(0 \%)$ & $6(10.4 \%)$ & $3(11.5 \%)$ \\
\hline Primary care & $85(56.7 \%)$ & $47(81 \%)$ & $18(69.3 \%)$ \\
General hospitals & $63(42 \%)$ & $5(8.6 \%)$ & $2(7.7 \%)$ \\
\hline Tertiary centres & $2(1.3 \%)$ & $0(0 \%)$ & $3(11.5 \%)$ \\
\hline Other settings & & & \\
\hline
\end{tabular}

Which statement best describes what you understand a biosimilar to

\begin{tabular}{|c|c|c|c|}
\hline $\begin{array}{l}\text { A new biological } \\
\text { medicine }\end{array}$ & $0(0 \%)$ & $2(3.5 \%)$ & $1(3.8 \%)$ \\
\hline $\begin{array}{l}\text { A generic biological } \\
\text { medicine }\end{array}$ & $30(20 \%)$ & $11(19 \%)$ & $1(3.8 \%)$ \\
\hline $\begin{array}{l}\text { A counterfeit copy of a } \\
\text { biological medicine }\end{array}$ & $2(1.3 \%)$ & $3(5.2 \%)$ & $1(3.8 \%)$ \\
\hline $\begin{array}{l}\text { A similar copy of a } \\
\text { biological medicine }\end{array}$ & $115(76.6 \%)$ & $31(53.4 \%)$ & $22(84.8 \%)$ \\
\hline $\begin{array}{l}\text { I have heard about } \\
\text { biosimilars, but I do not } \\
\text { know what they are }\end{array}$ & $2(1.3 \%)$ & $6(10.3 \%)$ & $0(0 \%)$ \\
\hline $\begin{array}{l}\text { I have never heard } \\
\text { about biosimilars }\end{array}$ & $1(0.6 \%)$ & $5(8.6 \%)$ & $1(3.8 \%)$ \\
\hline \multicolumn{4}{|c|}{ Are biosimilars on your local formulary? } \\
\hline Yes & $121(80.7 \%)$ & $33(57 \%)$ & $21(80.9 \%)$ \\
\hline No & $11(7.3 \%)$ & $7(12 \%)$ & $3(11.5 \%)$ \\
\hline I don't know & $18(12 \%)$ & $17(29.3)$ & $1(3.8 \%)$ \\
\hline Not applicable & $0(0 \%)$ & $1(1.7 \%)$ & $1(3.8 \%)$ \\
\hline
\end{tabular}

pharmacists (28\%) weighted increased patient acceptability as the least important of all the factors, whereas cost was an important consideration $(84 \%, 85 \%)$, respectively. Nurses (32\%) considered potential cost saving to the respondents' organisation as the least important of all the factors.

\section{Discussion}

This survey highlighted a variance in the level of knowledge and awareness of biosimilars between UK HCPs; pharmacists had the highest level of knowledge and awareness, followed by physicians, then nurses (Table 1).

Our study has some limitations. There were only a small number of pharmacist respondents, which may reflect the relative membership of the professional associations who supported the survey. It was not possible to calculate the response rate as the total number of members of the professional associations and societies are confidential. We would estimate that our response rate was relatively low. 


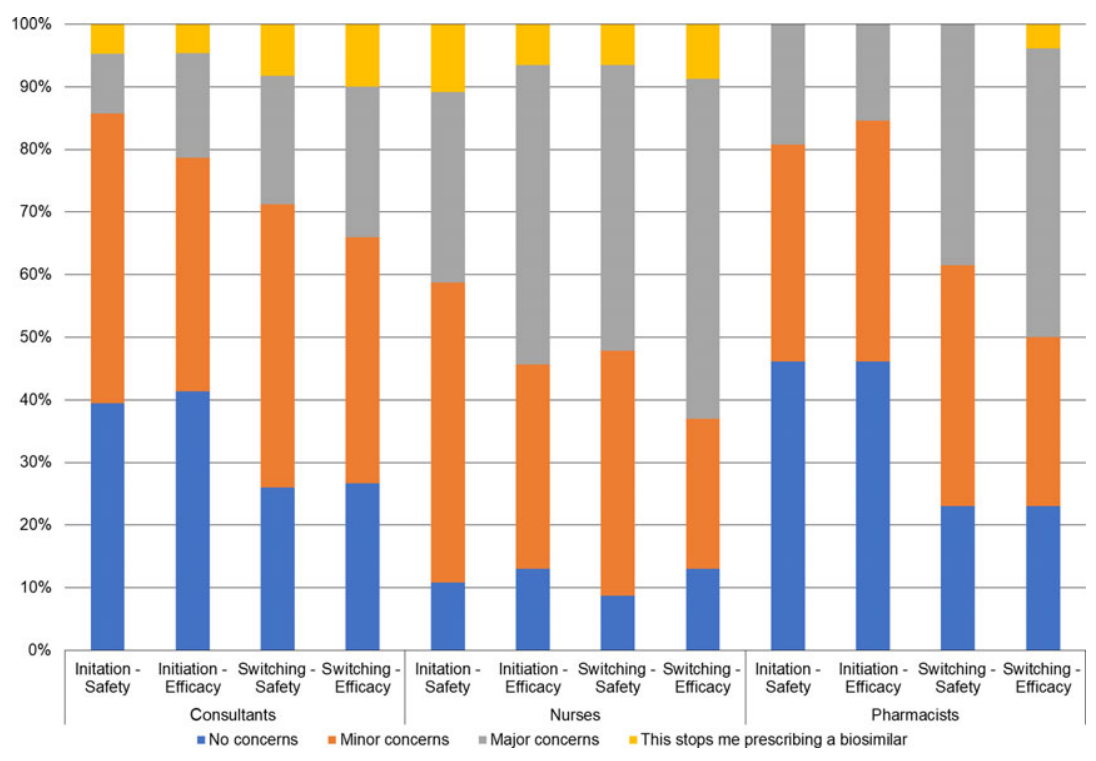

Figure 1 Respondents were asked 'how concerned are you about safety and efficacy when considering starting or switching to biosimilars?'

The lower level of nurse knowledge may be related to the fact that pharmaceutical marketing campaigns for biosimilar manufacturers are directed to physicians rather than nurses. Salem and Harvie's Australian study showed that nurses' training in new products such as biosimilars is often ad hoc and incomplete and they consequently had poor knowledge of safety and efficacy of drug groups. ${ }^{[5]}$ This is of concern as nurses in many cases are responsible for administering or supervising the patient's pharmacological regimen. The higher level of knowledge among pharmacists is not surprising as they are experts in medicines. ${ }^{[6]}$

Initiating biologics (originator or biosimilar) often rests with the responsible physician in consultation with the patient. In the UK, NICE Key Therapeutic Topic (KTT15) advised that biologics should not be automatically substituted by dispensing pharmacist. ${ }^{[7]}$ Therefore, the decision to switch to biosimilars (or to originator) is a multidisciplinary process involving the physician, patient, specialist nurse and pharmacist. ${ }^{[8]}$ Concerns about safety and efficacy when switching patients to biosimilars were high in all HCPs, but nurses had a higher level of (major) concerns than physicians and pharmacists, about the safety and efficacy of biosimilars when initiating in biologic naive patients. This may due to the fact that nurses had a lower level of knowledge of biosimilars (Table 1) and are less well informed about new medicines. ${ }^{[5]}$ In French study, Beck et al. ${ }^{[9]}$ showed that $67 \%$ of pharmacists had no concerns about safety and efficacy of biosimilars in general and 52\% of pharmacists were in favour of substitution of branded biologics to biosimilars; in France biosimilars substitution by community pharmacists is allowed. These results are not dissimilar to our results in relation to pharmacists' attitudes to biosimilars. Zelenetz et al. ${ }^{[10]}$ also showed that one-third of nurses indicated that they needed more information on biosimilars before making a decision about using and administering biosimilars.

Robust pharmacovigilance studies and guidance from NICE or other reputable national bodies were most likely to influence respondents to increase their utilisation and prescribing of biosimilars. This is not surprising as infliximab and insulin glargine biosimilars were only recently approved (in 2015), and there are relatively few studies on switching and long-term safety of these biosimilars. Interestingly, increased patient acceptability was the least important factor for physicians and pharmacists, but nurses were more interested in patients' acceptability and adherence to their treatment.

\section{Conclusion}

There is a variance in the level of understanding and attitude to biosimilars between professions, with a good level of understanding in medical consultants and pharmacists, but a lower level for nurses. Physicians and pharmacists had less concerns about initiating biosimilars than nurses, but all HCPs had high level of concerns in relation to switching.

\section{Declarations}

\section{Conflict of interest}

The Author(s) declare(s) that they have no conflicts of interest to disclose. 


\section{Funding}

This research received no specific grant from any funding agency in the public, commercial or not-for-profit sectors.

\section{Acknowledgements}

The authors would like to acknowledge all participating associations and societies committees, everyone who provided assistance in the dissemination of the survey, and all participants who completed the questionnaire. The authors would like to thank Zoe Swaine and Jonathan Underhill who participated in the pilot study. Mohammed Aladul was sponsored by the Higher Committee for Education Development in Iraq.
This research was approved by the Independent Peer Review Committee at Keele University.

\section{Authors' contributions}

Contributors All authors have contributed to this study, reviewed and approved the final version of the manuscript. SRC designed the study, interpreted the results and reviewed the manuscript and corrected the final version of the manuscript.RWF participated in the study design, interpreted the results and reviewed the manuscript and corrected the final version of the manuscript. MIA participated in the study design, data collection and interpretation of results, prepared the manuscript draft, and performed all analytical testing and manuscript review.

\section{References}

1. Owens DR et al. The emergence of biosimilar insulin preparations-a cause for concern? Diabetes Technol Ther 2012; 14: 989-996.

2. European Medicine Agency. European public assessment reports, http://www.ema.europa.eu/ema/index. jsp?status=Authorised \&alreadyLoaded $=$ true\&search $\mathrm{Tab}=$ searchByAuthType \&searchType $=$ name $\&$ curl $=$ pages $\% 2 \mathrm{~F}$ medicines\%2Flanding\%2Fepar_searc h.jsp\&searchGenericType=biosimilars \&keyword=Enter+keywords\&mid $=\mathrm{W}$ C0b01ac058001d124\&pageNo=1 2018, (accessed 4 February 2018).

3. Grabowski D et al. Attitudes towards subsequent entry biologics/biosimi- lars: A survey of Canadian rheumatologists. Clin Rheumatol 2015; 34: 1427-1433. https://doi.org/10.1007/ s10067-014-2835-4.

4. Cohen $\mathrm{H}$ et al. Awareness, knowledge, and perceptions of biosimilars among specialty physicians. Adv Ther 2017; 33: 2160-2172.

5. Salem L, Harvie B. Biosimilar medicines and their use: the nurses' responsibility. Ren Soc Aust J 2010; 6: 76-80.

6. Wiedenmayer K et al. Developing Pharmacy Practice: A Focus on Patient Care. Geneve: WHO, 2006 Netherlands.

7. NICE. Biosimilar medicines. https:// www.nice.org.uk/advice/ktt15/resourc es/biosimilar-medicines-58757954414 533. 2016, (accessed 22 June 2017).
8. The Association of the British Pharmaceutical Industry. EBE, EFPIA and IFPMA launch position paper on biosimilar switching decisions, http:// www.abpi.org.uk/media-centre/Partne r-organisation-statements/Pages/EBEEFPIA-and-IFPMA-launch-position-pa per-on-biosimilar-switching-decisions. aspx 2017, (accessed 22 June 2017).

9. Beck M et al. Knowledge, behaviors and practices of community and hospital pharmacists towards biosimilar medicines: results of a French webbased survey. MAbs 2017; 9: 383-390.

10. Zelenetz $\mathrm{AD}$ et al. NCCN biosimilars white paper: regulatory, scientific, and patient safety perspectives. $J$ Natl Compr Canc Netw 2011;9(Suppl 4): S1-S22. 